\title{
Effect of Energy Consumption in the Contact Zone on Machining Condition Optimization in Precision Surface Grinding
}

\author{
Yong Chen ${ }^{1,2, *}-$ Xun $\mathrm{Chen}^{3}-\mathrm{Xipeng} \mathrm{Xu}^{2}-\mathrm{Ge} \mathrm{Yu}^{4}$ \\ ${ }^{1}$ Huaqiao University, College of Mechanical Engineering and Automation, China \\ 2 Huaqiao University, Ministry of Education Engineering Research Center for Brittle Materials Machining, China \\ 3 Liverpool John Moores University, Faculty of Engineering and Technology, UK \\ 4 Jilin University, Roll forging institute, China
}

The instantaneous energy consumption in the grit-material interaction zone is an important indicator to represent the efficiency of grinding. In contrast to methods based on chip crack and formation or energy consumption from experimental measurement, this paper presents an improved differential model of energy consumption that takes account of dynamic grinding force, forced-vibration induced by the eccentrically grinding wheel rotation, and the phase difference between adjacent regenerative surface waviness. Furthermore, the vibratory amplitude and relevant frequency elements of a wheel-workpiece coupled system are analysed to optimize the key machining conditions involved in spindle speed, pack density of abrasive wheel and effective cutting space of adjacent contour grits in discrete transverse plane. It demonstrates that machining stability is the best when the phase difference value is $\pi / 2$ between continuously formed adjacent waviness generated by grit-workpiece interaction, i.e. the calculated value of instantaneous grinding energy consumption reaches its maximum value. In comparison to stable situations, an unstable grinding process is excited when the phase difference value is $3 \pi / 2$, i.e. micro-grinding force and vibration reinforce each other. It proves that a satisfied and stable grinding process can be controlled in real-time or in-situ by means of utilizing combination of optimal parameters, such as spindle speed, effective pack density, and the cutting space of abrasive grits. The presented mechanism is practical and can provide good guidance for further studies on machine-tool dynamics, time-domain or frequency-domain analysis of grinding vibration, and then on depth distribution of cut and ground surface accuracy.

Keywords: precision grinding, energy consumption, eccentrical vibration, machining stability, condition optimization

Highlights

- Improved differential models of undeformed chip thickness and grinding force were presented for the analysis of instantaneous energy consumption in grinding contact zone.

- $\quad$ Phase difference between adjacent surface waviness was investigated based on the regenerative vibration principle.

- Vibratory amplitude and relevant power-spectrum of a wheel-workpiece coupled system were investigated to develop strategies for optimizing key machining conditions.

- Machining stability is the best and the worst when the phase difference between adjacent continuous waviness generated by grit-workpiece interaction takes values of $\pi / 2$ and $3 \pi / 2$ respectively.

\section{INTRODUCTION}

Abrasive grinding, as a common precision machining technique, is used to achieve high surface quality in modern manufacturing. A multitude of abrasive grits with irregular characteristics and random distribution on the circumference of abrasive wheel conduct material removal and chip formation through three phases, e.g. rubbing, ploughing and cutting [1] and [2]. Under complicated machining conditions, chip formation in the grinding contact zone is difficult to characterize directly by the geometric-kinematic engagement process. With an increase of cutting depth between abrasive grits and workpiece, the energy consumption is increased due to more chip formation. Empirical or experimental results prove that most specific grinding energy is transmitted to the power loss in an abrasive wheel-workpiece vibratory system and the thermal energy consumption in the interface of grit-workpiece interaction, chips formation and coolant. Furthermore, the rest of the total energy is consumed to form residual strain in new finish surface and moving chips [3]. As a primary part of energy consumption, the energy consumed in the abrasive wheel-workpiece vibratory system leads to unavoidable chatter and a contrary effect on machining stability when the system is excited by forced-vibration and self-excited-vibration [4]. As a result, it leads to both poor surface quality and dimensional tolerance and shortens the lifetime of the abrasive wheel and machine spindle. Thus, for the machining process with the most stable situation, it is crucial to obtain required ground finish surface.

In addition to the investigations of the effects of non-linear transfer correlation or the mechanicalthermal interaction mechanism on grinding energy released from the material fracture in grit-material contact zone and leading to temperature elevation 
[5] and [6], many studies on the optimization of the surface topography characteristics of abrasive wheels [7] and machining conditions have been conducted based on minimal energy consumption or a material removal mechanism under different grinding phases [8] to [10]. The relevant experiments are also performed to validate these research findings. In these studies, grinding energy consumed by mechanical vibratory motion is commonly negligible, and the depth of cut is often set as constant. Such assumptions are made to simplify the analysis of grinding mechanism but weaken the correlated relationship between grinding conditions and ground surface qualities in mathematical models and will further increase the difficulties in understanding the entire energy consuming mechanism of the grinding process.

Based on previous works on the microscopic mechanism model of grit-material interaction in the surface grinding process, this paper analyses the energy consumption in the contact zone to reveal the phase difference between adjacent vibration waviness in terms of regenerative motion. The depth of cut and the instantaneous energy consumption are analyzed in terms of forced- and self-excited- vibration models, which are derived from two important, influential factors to machining stability, i.e. the external eccentrically rotational behavior of abrasive wheel and internal regenerative motion. Relevant experimental investigations are conducted to validate the effectiveness of presented models. Finally, optimization strategies of energy consumption to achieve stable process are presented under conditions combination of spindle speed, pack density of abrasive wheel and effective cutting space of adjacent contour grits.

\section{GRINDING FORCE MODEL}

To model grinding dynamic performance and describe the plastic-metal material removal process, a typical motion trajectory of single active abrasive grit in surface down-grinding presented by Werner et al. is illustrated in Fig. 1a [11]. The trajectory is a combination of rotational motion (abrasive grit) and linear motion (workpiece). Meanwhile, the material flow trajectory of chip formation is depicted depending on the penetration depth of abrasive grit in Fig. 1b [1]. In Fig. 1a, the entire volume of workpiece material in shadow area is removed under predefined grinding conditions. To focus on the kinematic analysis of material removal process, the elastic deformation and material ploughing behavior induced by abrasive grit are neglected. Furthermore, the energy consumption in relation to frictional abrasion and thermal transfer behavior is negligible. Effect of energy consumption in the $Z$-axial direction on machining stability is also not considered in this study due to a negligibly smaller proportion of grinding force in $Z$-axial direction compared to those in feed and normal directions.

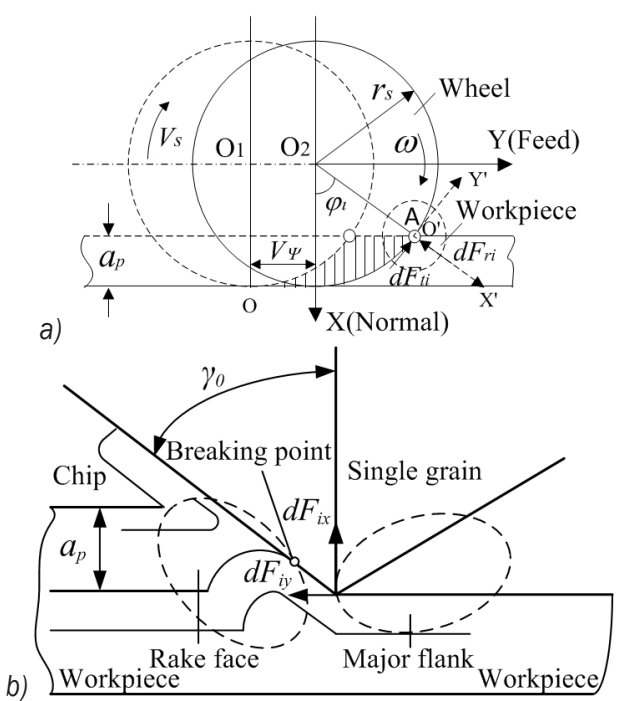

Fig. 1. Schematic illustration of grinding principle of single abrasive grit; a) motion trajectory of single abrasive grit; and

b) flow trajectory of removed material in contact zone

As shown in Fig. 1a, single abrasive grit ' $A$ ' positioned at the start point of the engaging-in section in an equally spaced plane with differential dz height that is perpendicular to the $Z$-axial is investigated in surface grinding. With increasing depth of cut in the contact zone, the instantaneous grinding force acting on grit ' $A$ ' is divided into two parts in the tangential and radial directions. These forces are expressed as [11]:

$$
\left[\begin{array}{c}
\mathrm{d} F_{t i} \\
\mathrm{~d} F_{r i}\left(\varphi_{i}\right)
\end{array}\right]=\left[\begin{array}{c}
K_{s} \\
c K_{s}
\end{array}\right]\left[\frac{V_{w}}{V_{s}}\right]^{2 \varepsilon-1}\left[d_{s}\right]^{1-\varepsilon} t_{i}\left(\varphi_{i}\right) \mathrm{d} \varphi,
$$

where $K_{s}$ is specific grinding force at certain grinding conditions; $c$ is a proportion factor to represent the grinding ratio of the tangential force and radial force; $V_{w}$ and $V_{s}$ are the feed speed of workpiece and peripheral speed of grinding wheel, respectively; $d_{s}$ is diameter of abrasive wheel; $t_{i}\left(\varphi_{i}\right)$ is defined as instantaneous undeformed chip thickness; index $\varepsilon$ is comprehensive influential coefficient of grit 'A' which is related to its sharpness and frictional behaviour; variable $\varphi_{i}$ is rotational position angle of some grit ' $i$ ' at the time interval $T$ in the cross-section plane and is depicted as: 


$$
\varphi_{i}=\varphi_{0 i}+\theta+(i-1) \frac{2 \pi}{m},
$$

where $\varphi_{0 i}$ is defined as initial position angle between the grit ' $i$ ' and the vertical plane that contains the spindle axis of the abrasive wheel; $\theta=\omega T$ is calculated as the rotational angle of spindle of the abrasive wheel with angular velocity $\omega$ within a time interval $T$, in which the adjacent active abrasive grits scratch through the same position. Variable $m$ is related to pack density of abrasive wheel and could be represented as the number of active abrasive grits in contact zone in the cross-section plane.

Combined with the forces in the tangential and radial directions, instantaneous forces in the normal $(X)$ and feed $(Y)$ directions in global coordinates are rearranged as:

$$
\left[\begin{array}{l}
\mathrm{d} F_{i x} \\
\mathrm{~d} F_{i y}
\end{array}\right]=\left[\begin{array}{cc}
-\sin \varphi_{i} & -\cos \varphi_{i} \\
\cos \varphi_{i} & -\sin \varphi_{i}
\end{array}\right]\left[\begin{array}{l}
\mathrm{d} F_{t i}\left(\varphi_{i}\right) \\
\mathrm{d} F_{r i}\left(\varphi_{i}\right)
\end{array}\right] .
$$

\section{MODELLING OF UNDEFORMED CHIP THICKNESS}

Regarded as the most important dynamics factor, the interactive mechanism of the combination of regenerative vibration and eccentric motion in grinding is shown in Fig. 2. It has a great influence on machining stability, dynamic depth of cut and dimensional tolerance in grinding [4].

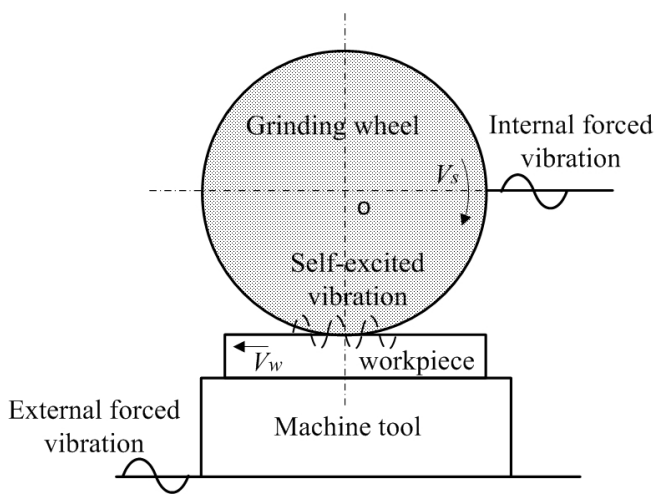

Fig. 2. Chatter vibration mechanism in grinding

It is mainly manifested that in a typical grinding contact zone,material surface waviness that results from previous active abrasive grit is substituted for the next new generated waviness with the phase and magnitude difference in terms of the regenerative principle because of the eccentrically rotational behaviour of grinding wheel. The regenerative vibration principle is depicted as a continuously relative vibration between abrasive grit and workpiece in the contact zone during the abrasive grit-material interactive period. The effect of the regenerative principle is great on instantaneous chip formation and further on the micro-grinding force of each grit. The eccentrically rotational behaviour of a grinding wheel is the structural vibration that transfers from the rotating spindle of the machine tool, the moving platform of the workpiece, the centrifugal force of grinding wheel and nonuniform wear of abrasive grits on the wheel surface. With subsequent increasing depth of cut, the machining vibration system could be excited greatly at very close frequency between the generated surface waviness and machine-tool spindle motion, which results to a large additional variation of depth of cut leading to chatter. Furthermore, abrasive grits could be damaged and fall away due to great impact, and low surface quality became evident.

Based on the analysis of regenerative principle and eccentric behaviour of abrasive wheel, instantaneous chip thickness is comprised of three parts, i.e. statics chip thickness, regenerative chip thickness and eccentric chip thickness, and then is characterized as:

$t_{i}\left(\varphi_{i}\right)=\left\{\begin{array}{c}t_{0}+\Delta t_{i}+\delta t_{i}\left(\varphi_{i}\right) \quad \text { when } 0 \leq \varphi_{i} \leq \Omega \\ 0 \quad \text { when out of contact zone }\end{array}\right.$

(1) Statics chip thickness $t_{0}$

$t_{0}$ is calculated as $t_{0}=f_{t} \sin \left(\varphi_{i}\right)$. Where $f_{t}$ is the feed per revolution [14]. Total depth of cut $a_{p}$ is shown in Fig. 1a. Statics chip thickness is an important and simplified intermediate variable of grinding dynamics in many previous research works [12] to [14].

(2) Regenerative chip thickness $\Delta t_{i}$ $\Delta t_{i}$ is defined as relevant dynamic displacement in radial direction derived from regenerative vibration trajectory in grit-material contact zone, characterized as:

$$
\Delta t_{i}=\left(H_{i s(-T)}-H_{i s}\right)-\left(H_{i w(-T)}-H_{i w}\right),
$$

where $H_{i s}, H_{i s(-T)}, H_{i w}, H_{i w(-T)}$ are respectively dynamic displacements of the current and the previous grit-workpiece pairs in radial direction at the same instantaneous position angle $\varphi_{i}$ within a time interval $T$. Meanwhile, it is noted that surface waviness with different phase is formed while the material is removed by adjacent active grinding grits.

(3) Eccentric chip thickness $\delta t_{i}\left(\varphi_{i}\right)$

$\delta t_{i}\left(\varphi_{i}\right)$ is expressed as dynamic chip thickness deviation excited by eccentrically rotational 
behaviour of abrasive wheel and machine-tool spindle, calculated by:

$$
\begin{aligned}
& \delta t_{i}\left(\varphi_{i}\right)=R_{i}^{\prime}\left(\varphi_{i}^{\prime}\right)-R_{i-1}^{\prime}\left(\varphi_{i}^{\prime}\right)= \\
& \sqrt{R^{2}+\delta_{e}^{2}-2 R \delta_{e} \cos \left(\pi-\left|\varphi_{0 i}-\varphi_{e i}+2(i-1) \frac{\pi}{m}\right|\right)}- \\
& \sqrt{R^{2}+\delta_{e}^{2}-2 R \delta_{e} \cos \left(\pi-\mid \varphi_{0(i-1)}-\varphi_{e(i-)}+2(i-2) \frac{\pi}{m}\right)},
\end{aligned}
$$

where variables $R_{i}{ }^{\prime}$ and $R$ are the radius of rotating spindle of machine-tool and abrasive wheel, respectively. Variable $\delta_{e}$ which is defined as wheel eccentricity can be measured by means of dynamic balancing experiment (using a tactile measuring sensor on the inspection). Variable $\varphi_{e i}$ that is relative position angle of the grit ' $i$ ' between actual rotating centre of abrasive wheel and machine-tool spindle can be examined in terms of clamping position in preparation phase prior to grinding.

\section{PHASE CHARACTERIZATION OF SURFACE WAVINESS OF MATERIAL}

The number of active abrasive grits (i.e. effective cutting edges) can be measured in the contact zone along trajectory arc, as shown in Fig. 1a by utilizing a set of quick-stop device that interrupts chip formation process in $1 \mathrm{~ms}$ to $5 \mathrm{~ms}$ leaving countable chip roots with diverse shapes, such as segmented chips, continuous chips, lateral chips, which are formed by active grits; or by using a high speed camera to identify the different phases of chip formation in $0 \mathrm{~ms}$ to 1.75 $\mathrm{ms}$. The measurement accuracy is closely related with current grinding speed, feed speed of workpiece, depth of cut and abrasive wheel specification [15] to [17]. The effective cutting edges and cutting space between adjacent contour grits are illustrated in Fig. 3 [1] and [3]. It shows that four active abrasive grits whose protrusion heights are over the baseline of depth of cut $a_{p}$ will scratch through material surface and produce regenerative waviness while engagingin and engaging-out in the contact zone. In contrast, the edges of abrasive grits below the baseline of depth of cut $a_{p}$ will not engage the grinding process as they barely encounter material in contact zone.

There are generally several cutting edges that are located on each grit surface and available to remove material, which is proven by means of microscopic experiments in many previous works [16].

Thus far, it is acceptable for the CIRP organization that only one effective edge of each grit exists at the moment of the penetrating process as there is too small as cutting space between adjacent cutting edges on working grits (e.g. grit spacing span $\lambda_{s}$ is shown in Fig. 3) to contain or form chips in grinding. Thus, the number of effective cutting edges is approximately equal with the active abrasive grits due to unavailable chip space [18] and [19]. It is important to identify the peak number of material surface waviness with accordance of active abrasive grits.

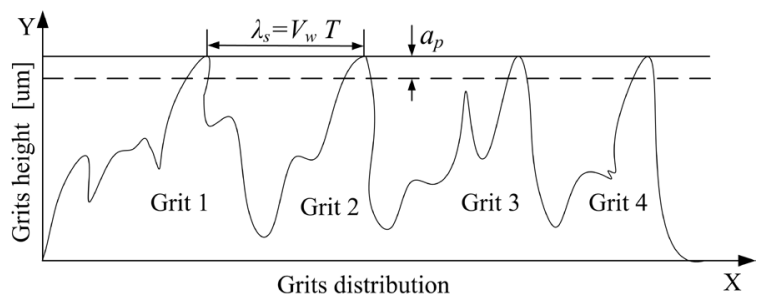

Fig. 3. Grits distribution in contact zone

Based on the analysis of undeformed chip thickness, material surface waviness that results from the regenerative vibration of grit-workpiece interaction is related the contact arc length and the time interval while the adjacent active grits scratch through the contact zone. As shown in Fig. 1a, a local reference coordinate system $O^{\prime} X^{\prime} Y^{\prime}$ is applied to the selected grit ' $\mathrm{A}$ ' positioned in the equally spaced $\mathrm{d} z$ plate. In the coordinate system, instantaneous the engagement position of effective cutting edge of grit ' $\mathrm{A}$ ' is defined as the original centre $O$ ' and directions in tangential and radial of the grit edge are regarded as dynamic axial $Y^{\prime}$ and $X^{\prime}$, respectively. The positive directional axial $X^{\prime}$ is perpendicular towards the material surface.

The moving trajectory of adjacent effective cutting edges of abrasive grits with the similarly excited regularity is illustrated in Fig. 4. According to an analysis of machining stability based on the regenerative mechanism in Section 2, the correlation between machine-tool spindle speed and inherent chatter frequency has a great influence on dynamic depth of cut of abrasive grit [20] and [21]. Considering the scratching process of two adjacent active abrasive grits, the continuous contour of material surface in contact zone would appear as $k+\sigma$ waves, in which $k$ is assumed as a positive integer $(k=1,2,3, \ldots)$. In particular, the distribution of the surface waviness is closely related with the distribution of depth of cut in the contact zone which can be extracted from intersections between the moving trajectory of active abrasive grits and equally spaced discrete planes along the contact arc length. 
The moving trajectory of each grit is assumed to be a sinusoidal curve. The fractional variable $\sigma$ is used to define $\psi=2 \pi \sigma(0 \leq \sigma<1)$, which represents the phase difference between previous waved trajectory (vibration amplitude takes value of $X_{p}$ ) and current waved trajectory (vibration amplitude takes value of $X_{c}$ ) with the same vibratory frequency.

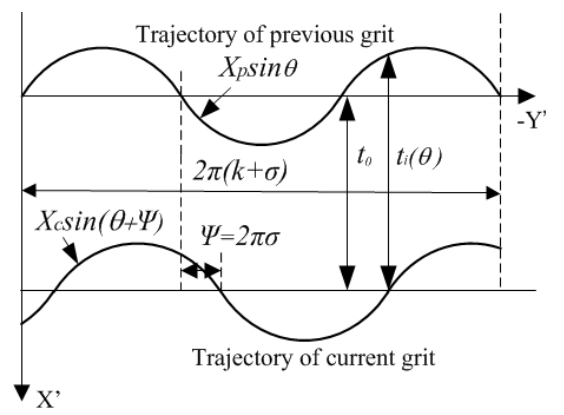

Fig. 4. Vibratory trajectory of adjacent abrasive grits in contact zone

Assuming $n[\mathrm{rev} / \mathrm{min}]$ is the spindle speed of the machine tool, $m$ is the number of active abrasive grits (i.e. the number of effective cutting edges) along the wheel surface, the vibratory frequency $f[\mathrm{rad} / \mathrm{s}]$ of the machine-tool spindle-abrasive wheel system could be obtained by means of a power spectrum analysis of the abrasive wheel in the time interval $T$. The interrelationship of the number of surface waviness retained by continuous effective cutting edges and inherent vibratory frequency of the spindle-wheel system is calculated as $k+\sigma=f \cdot T$, and then,

$$
\frac{f}{k+\sigma}=\frac{1}{T}=\frac{m n}{60} .
$$

Based on Eq. (7), the phase difference of adjacent surface waviness takes values of zero or $2 \pi$, when division ratio of the spindle speed and vibratory frequency of the system is a positive integer. It implies that the adjacent formed surface waviness is parallel, and the chip thickness keeps constant at the same position in the contact zone. Nevertheless, the dynamic depth of cut in the contact zone is continuously varying in terms of the regenerative principle during grinding process, which results in the value of the adjacent phase difference not being equal to zero or $2 \pi$.

\section{INSTANTANEOUS ENERGY CONSUMPTION IN CONTACT ZONE}

To investigate the micro-grinding process of continuous active grits, the surface waviness amplitudes generated by two adjacent abrasive grits in a radial direction take values of $X_{p}$ and $X_{c}$, respectively, as shown in Fig. 4 and are depicted by:

$$
\begin{gathered}
x_{p}(\theta)=X_{p} \sin \omega t=X_{p} \sin \theta, \\
x_{c}(\theta)=X_{c} \sin (\omega t+\psi)=X_{c} \sin (\theta+\psi) .
\end{gathered}
$$

Assuming the elastic and ploughing formations of workpiece material are negligible in grinding the depth of cut according to Eq.(4) is found as:

$$
t_{i}\left(\varphi_{i}\right)=t_{0}+\Delta v_{i}+\delta t_{i}\left(\varphi_{i}\right)=t_{0}+x_{c}(\theta)-x_{p}(\theta)+\delta t_{i}\left(\varphi_{i}\right) .
$$

Furthermore, neglecting energy consumption for elastic deformation, frictional abrasion, and thermal transmission, a mechanical energy model is developed below to present, the material removal process with the grinding force in radial direction perpendicular to material surface and the depth of cut according to Eqs. (1) and (10).

$$
W_{i}=-\int c k_{s}\left[\frac{v_{w}}{v_{s}}\right]^{2 \varepsilon-1}\left[d_{s}\right]^{1-\varepsilon} t_{i}\left(\varphi_{i}\right) d\left(x_{c}(\theta)\right),
$$

where the minus sign represents that the grinding force in radial direction is always pointing to the opposite direction of vibration displacement of abrasive grit.

Eqs. (8) to (10) are substituted into Eq. (11), then integrated as follows:

$$
\begin{aligned}
& W_{i}(\theta)=-c K_{s}\left[\frac{v_{w}}{v_{s}}\right]^{2 \varepsilon-1}\left[d_{s}\right]^{1-\varepsilon} X_{c} \times \\
& {\left[\frac{1}{2} X_{c} \sin ^{2}(\theta+\psi)-X_{p} W_{0}(\theta)+\left(t_{0}+\delta t_{i}\left(\varphi_{i}\right)\right) \sin (\theta+\psi)\right],}
\end{aligned}
$$

where

$W_{0}(\theta)=\frac{1}{2} \cos \psi \sin ^{2} \theta-\frac{1}{2} \theta \sin \psi-\frac{1}{4} \sin \psi \sin 2 \theta$.

Due to the rational angle value $\theta$ of abrasive grits from zero to $2 \pi$ in each revolution period, the energy consumption is obtained as follows:

$W_{i}=\left.W_{i}(\theta)\right|_{0} ^{2 \pi}=-\pi c K_{s}\left[\frac{v_{w}}{v_{s}}\right]^{2 \varepsilon-1}\left[d_{s}\right]^{1-\varepsilon} X_{p} X_{c} \sin \psi$.

In Eq. (12), the vibrated grits always consume energy when the phase difference value of the adjacent surface waviness is in the range of zero and $\pi$. In such a case, the varying direction of instantaneous force is always opposite to vibratory direction of abrasive grit, which results in a reduction of the vibratory intensity of abrasive grits and to stabilize process in accordance with regenerative principle. At a certain condition, when $\psi=\pi / 2$ or corresponding $\sigma=0.25$, the energy 
consumption in a periodic revolution reaches the most negative limit, the most stable machining process is achieved accompanied with high surface quality.

In contrast, when both varying directions of instantaneous force and abrasive grit vibration keep the same trend, i.e. the phase difference value of adjacent surface waviness is in the range of $\pi$ and $2 \pi$, the force facilitate the vibration of grits together and then unstable process occurs. At a certain condition, when $\psi=3 \pi / 2$ or $\sigma=0.75$, the energy consumption in a periodical revolution reaches to its positive maximum limit, the most unstable process is achieved.

\section{OPTIMIZATION STRATEGIES AND EXPERIMENTAL ANALYSIS}

\subsection{Experimental Preparation}

By adjusting optimal conditions, e.g. the phase difference value $\psi$ and variable $\sigma$ or the number $m$ of active abrasive grits in the contact zone and spindle speed $n$ of machine-tool off-line, a stable grinding process would be obtained. A series of experiments are performed under specific machining conditions as follows. Monolayer diamond grinding wheel with electroplated grits (average size is $90 \mu \mathrm{m}$ ) is applied to conduct grinding experiments. The sample material is low carbon steel EN8. Abrasive wheel specification takes values of diameter $\phi 200 \mathrm{~mm}$, width $20 \mathrm{~mm}$, average wedge angle $30^{\circ}$, pack density 5 per $\mathrm{mm}^{2}$ in transversal plane, grits spacing $200 \mu \mathrm{m}$ between adjacent abrasive grits. Depth of cut is $15 \mu \mathrm{m}$, grinding speed is $46 \mathrm{~m} / \mathrm{s}$, spindle speed is $4456 \mathrm{rev} / \mathrm{min}$, workpiece speed is $100 \mathrm{~mm} / \mathrm{s}$. The maximum eccentricity of grinding wheel is examined of $1 \mu \mathrm{m}$. Specific grinding energy is approximately $20 \mathrm{~J} / \mathrm{m}^{3}$. The force ratio between tangential and normal directions is 0.145 . The original position angle of the abrasive wheel is $0.1 \pi \mathrm{rad}$.

\subsection{Analysis of Experimental and Simulation Results}

To validate presented dynamics models according to Eqs. (3) and (4), a test platform is set up as shown in Fig. 5 to collect and analyse dynamics signals in the grinding process. All measurement procedures are fulfilled on a surface grinding machine tool MSG250HMD. A piezoelectricity dynamometer of Kistler 9257BA that connects with a Dewe2010 signal analyser and a computer is fixed between workpiece and moving table to collect grinding force signals in normal and feed directions. The sampling frequency of the dynamometer is set to $50 \mathrm{kHz}$.

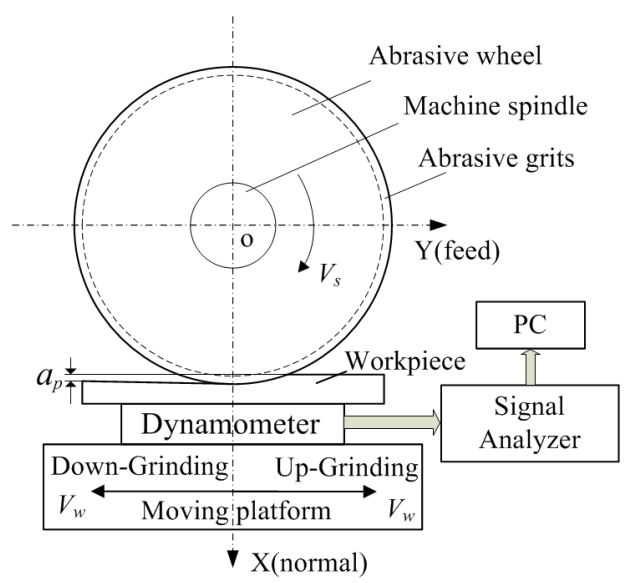

Fig. 5. Test platform of abrasive grinding dynamics

Under the machining conditions in Section 5.1, a series of experimental and simulation results in both normal and feed directions are illustrated in Fig. 6. The absolute mean values of adjacent peak and bottom values of specific force signals in each typical rotational period of the grinding wheel are extracted from a constant interval of 1 millisecond period (i.e. average of every 50 sample points). It can be seen that the maximum value and development tendency of the simulated results are consistently close to the experimental specific grinding forces in both directions with an acceptable mean deviation of $12.5 \%$.
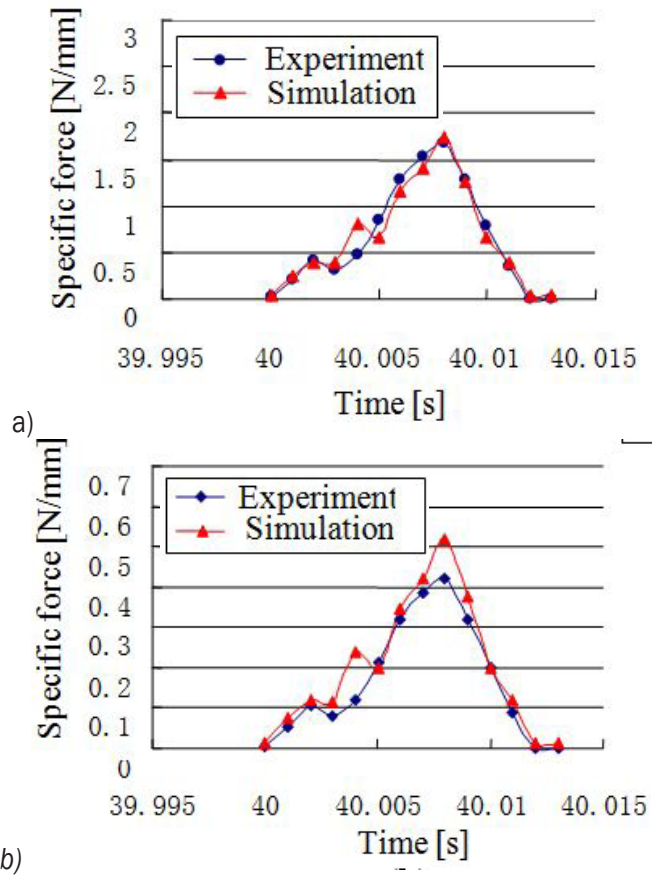

Fig. 6. Comparison of specific grinding force between tests and simulation;a) in normal direction; b) in feed direction 


\subsection{Optimization strategies of Machining Conditions}

Based on the analytic model calculation, further simulation analysis of the vibratory displacement and frequency analysis of abrasive wheel-workpiece system under the same conditions in Section 5.1 are carried out in the normal direction $(X)$ and feed direction $(Y)$. The results are depicted in Fig. 7a and Fig. 7b. This demonstrates that the vibratory frequency of principal modal mode (i.e. waviness with peak amplitude), the second and the third modes of abrasive wheel take values of $495 \mathrm{rad} / \mathrm{s}(78.8$ $\mathrm{Hz}), 900 \mathrm{rad} / \mathrm{s}(143.3 \mathrm{~Hz})$ and $1350 \mathrm{rad} / \mathrm{s}(215 \mathrm{~Hz})$ respectively due to the forced-vibrations caused by the centrifugal force of the rotational machine-tool spindle and abrasive wheel according to the power

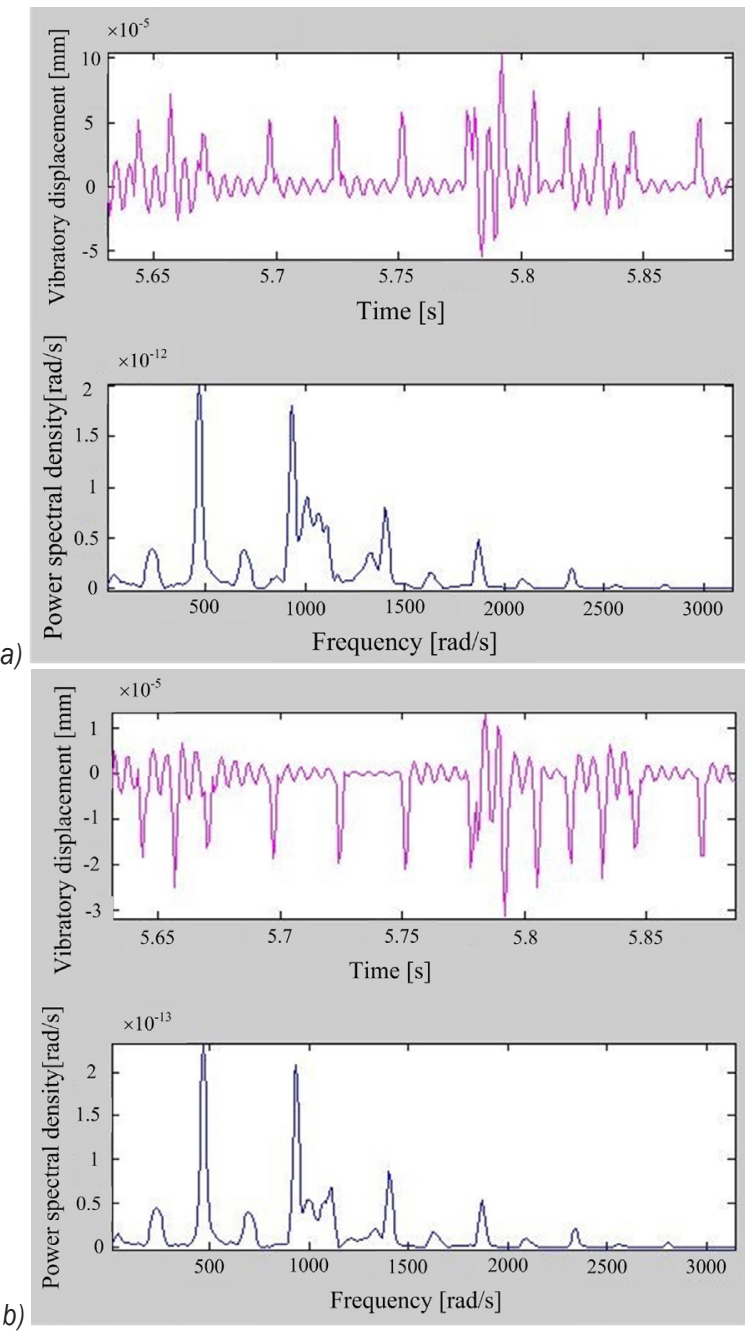

Fig. 7. Relative vibratory displacement and its power spectrum of wheel-workpiece grinding system; a) in normal direction; b) in feed direction $\left(a_{p}=15 \mu \mathrm{m}, V_{\mathrm{s}}=46 \mathrm{~m} / \mathrm{s}, V_{w}=100 \mathrm{~mm} / \mathrm{s}\right.$, $n=4456 \mathrm{rev} / \mathrm{min}, \mathrm{m}=5$ ) spectrum analysis in Fig. 7. Considering the relative vibratory amplitude variation of the wheel-workpiece system, it is in the range of $\left[-6 \times 10^{-5}, 1 \times 10^{-5}\right] \mathrm{mm}$ and mainly in the range of $\left[-5 \times 10^{-5}, 6 \times 10^{-5}\right] \mathrm{mm}$ in the normal direction; Meanwhile, the vibratory amplitude varies in the range of $\left[-3 \times 10^{-5}, 1.5 \times 10^{-5}\right]$ $\mathrm{mm}$ and mainly in the range of $\left[-2 \times 10^{-5}, 1 \times 10^{-5}\right]$ $\mathrm{mm}$ in the feed direction. Note that the presented magnitudes of samples are local mean values rather than exact peaks or bottoms because of the frequency limitation of collected samples. The mean deviation of vibratory amplitude in normal direction derived from eccentrically rotational behaviour of abrasive wheel and regenerative theory is approximately $5 \%$ in comparison to the static depth of cut in the contact zone.

\section{(1) Optimization of spindle speed of machine-tool}

Assuming that the number and topography of active grits in the contact zone remain unchanged (i.e. attrition wear and breakage of abrasive grits will not occur) in an ideal grinding process, relevant machining conditions and vibratory frequency of the principal modal are taken into Eq. (7) to obtain waviness number $k+\sigma$. As the aforementioned analysis on the excited-vibration of machining system, the vibratory amplitude can be great while value $k+\sigma$ is in the range of $[n+0.5 n+1]$ (where $n$ is a positive integer). To achieve stable process in which energy consumption reaches the most negative limit, variable $\sigma$ is set to 0.25 and is rearranged to Eq. (7) to obtain rounded integer $k=1$. It implies that there is approximate one waviness as each active grit scratches through the contact length under vibratory frequency conditions. The spindle speed $n$ is calculated after all variables are taken into Eq. (7). With the adjusted variable value of $n=4752 \mathrm{rev} / \mathrm{min}$ (i.e. renewed process condition), the relative vibratory displacement of the wheelworkpiece system in normal and feed directions are illustrated in Fig. 8, respectively.

It shows in Fig. 8a that the vibratory amplitude in the normal direction with periodical variation is mainly in the range of $\left[-3 \times 10^{-5}, 1.5 \times 10^{-5}\right] \mathrm{mm}$ and a few of them vary in the range of $\left[-6 \times 10^{-5}, 9 \times 10^{-5}\right] \mathrm{mm}$ due to momentary cutting-in or cutting-out impact. It demonstrates that in comparison to vibratory amplitude at the stable machining conditions with spindle speed $4456 \mathrm{rev} / \mathrm{min}$, it is still reduced to $20 \%$ by means of a slight adjustment of spindle speed (i.e. a change from $4456 \mathrm{rev} / \mathrm{min}$ to $4752 \mathrm{rev} / \mathrm{min}$ ) to avoid the inherent dominant frequency of the machinetool even though a stable process is conducted under regular process or experimental conditions. 
Similarly, Fig. $8 \mathrm{~b}$ shows that the vibratory amplitude in the feed direction with periodical variation is mainly in the range of $\left[-1 \times 10^{-5}\right.$, $\left.0.75 \times 10^{-5}\right] \mathrm{mm}$ and a few of them vary in the range of $\left[-2.5 \times 10^{-5}, 1.3 \times 10^{-5}\right] \mathrm{mm}$. The reduced value of approximately $25 \%$ of vibratory amplitude is taken in comparison to the one under the stable machining conditions.

Comparing the situations before and after the adjustment of spindle speed, the vibratory waviness amplitude is obviously reduced by the adjustment, leading to a stable machining process with low magnitude of vibration. Meanwhile, the principal frequency of the system moves to higher-frequency domain around $1200 \mathrm{rad} / \mathrm{s}$.
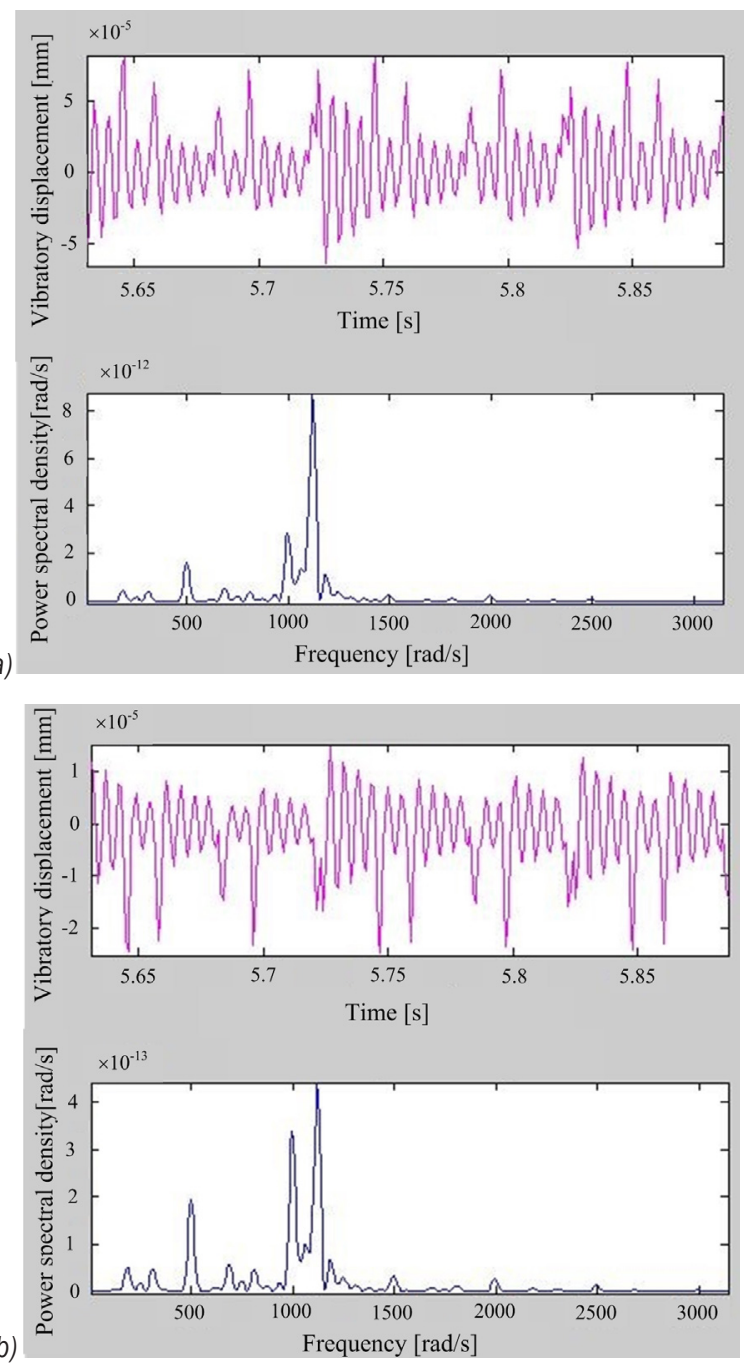

Fig. 8. Relative vibratory displacement of wheel-workpiece system with optimal spindle speed; a) in normal direction; b) in feed direction $\left(a_{p}=15 \mu \mathrm{m}, V_{s}=50 \mathrm{~m} / \mathrm{s}\right.$, $V_{w}=100 \mathrm{~mm} / \mathrm{s}, n=4752 \mathrm{rev} / \mathrm{min}, \mathrm{m}=5$ )
Then renewed dominant and second frequency of $1200 \mathrm{rad} / \mathrm{s}$ and $1000 \mathrm{rad} / \mathrm{s}$ respectively, shown in Fig. 8 , are generated while the process gradually tends to stability. The inherent low-frequency $495 \mathrm{rad} / \mathrm{s}$ which prevails before speed adjustment transfers to the third mode of the system as renewed principal frequency at the most stable machining situation is far from the low-frequency domain. Note that a little vibration with high amplitudes remains in a narrow range because instantaneous impact on the system is unavoidable while abrasive grits penetrate in the material, and chips are formed.

\section{(2) Optimization of pack density and grit spacing of abrasive wheel}

Here, it is assumed that the spindle speed of the machine tool is constant, i.e. $n=4752 \mathrm{rev} / \mathrm{min}$. It presents that structural modal frequency of the principal mode, second mode and third mode that are commonly excited from rotating spindle will not vary during the grinding process. Machining stability is analysed in accordance with adjusted pack density or grit spacing (by dressing procedure) of the abrasive wheel. The number of active abrasive grits in a specific cross-sectional plane whose direction is transverse to $Z$-axial takes values of 4 or 6 . The resulting periodical vibratory amplitude in normal and feed directions is illustrated in Figs. 9 and 10, respectively. It shows that the amplitudes are mainly in the range of $\left[-5 \times 10^{-5}, 5 \times 10^{-5}\right] \mathrm{mm}$ in the normal direction and in the range of $\left[-2 \times 10^{-5}, 1 \times 10^{-5}\right] \mathrm{mm}$ in the feed direction. The mean values of the vibratory amplitudes in both directions are approximately the same as those under optimal spindle speed conditions. The amplitude of abrasive wheel with low packing density tends to a stable machining process with better damping tendency and lower values. This is because the grinding force in the contact zone decreases with less active abrasive grits involved in grinding process.

Note that in the narrow high-frequency domain, principal frequency $1100 \mathrm{rad} / \mathrm{s}$ with peak value is so close with second mode $1200 \mathrm{rad} / \mathrm{s}$, which easily makes excitation together due to energy leakage. Thus, when abrasive wheel with low packing density is applied to conduct stable grinding process under mentioned machining conditions, the principal mode of the machine tool needs to enhance to prevent the superimposed magnitude of the adjacent modes.

\section{(3) 3D ground surface topography analysis at different optimization strategies}

With different optimization strategies (i.e. adjustment of spindle speed, packing density of 

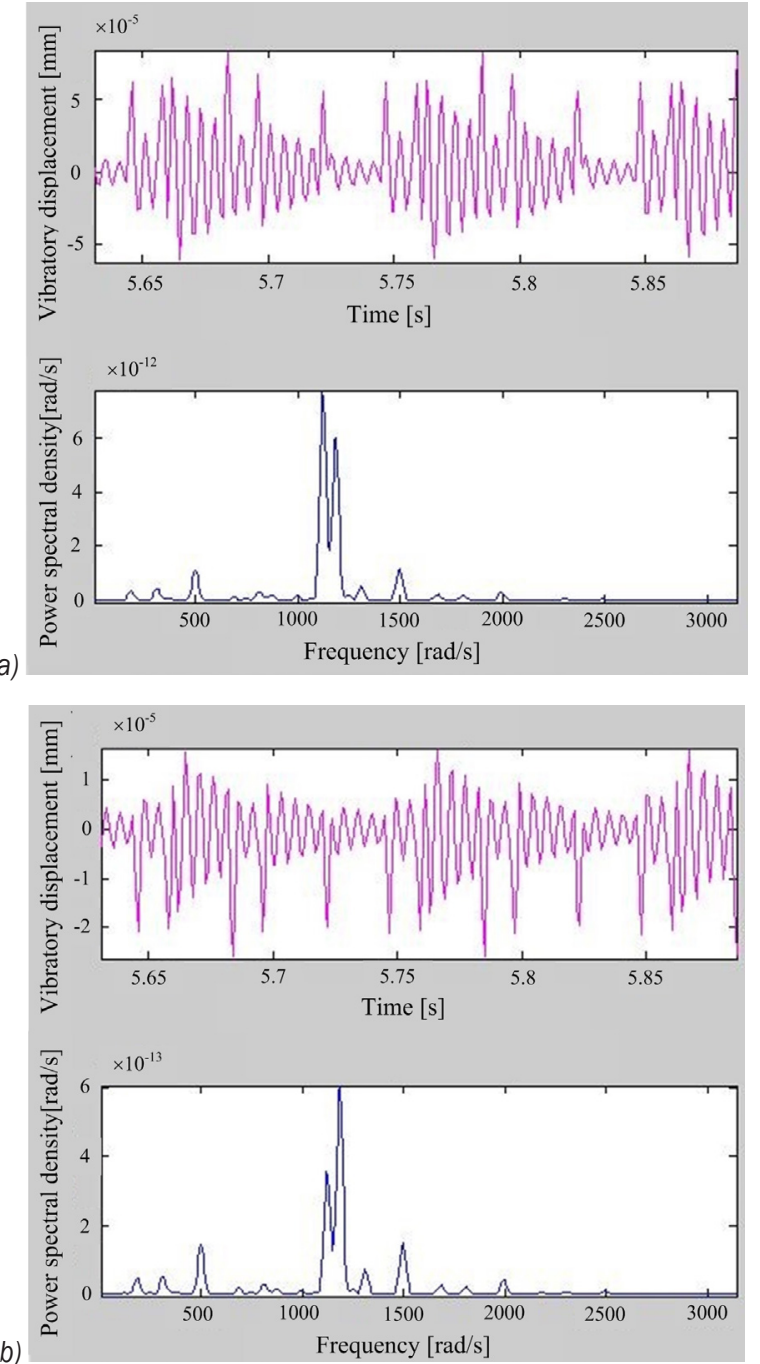

Fig. 9. Vibratory displacement of wheel-workpiece grinding system with optimized numbers of grits; a) in normal direction; b) in feed direction, $\left(a_{p}=15 \mu \mathrm{m}, V_{\mathrm{s}}=50 \mathrm{~m} / \mathrm{s}\right.$, $V_{\mathrm{w}}=100 \mathrm{~mm} / \mathrm{s}, n=4752 \mathrm{rev} / \mathrm{min}, \mathrm{m}=4$ )

abrasive wheels), three finished ground surfaces in the normal direction are presented in Fig. 11. It has been proven that it only requires few some tens of milliseconds for active abrasive grits to scratch through entire contact zone and finish grinding by means of kinematics analysis of high-speed camera system [16] and [17]. It implies that the arc length of the effective contact edge is in the range of few hundreds of microns. Comparing bigger impact of abrasive grits while penetrating in and exit from material surface with normal vibration in the stable grinding process, the numbers of vibratory peak and bottom vertices with different regenerative phase amplitudes in the contact zone are the same as those of known active
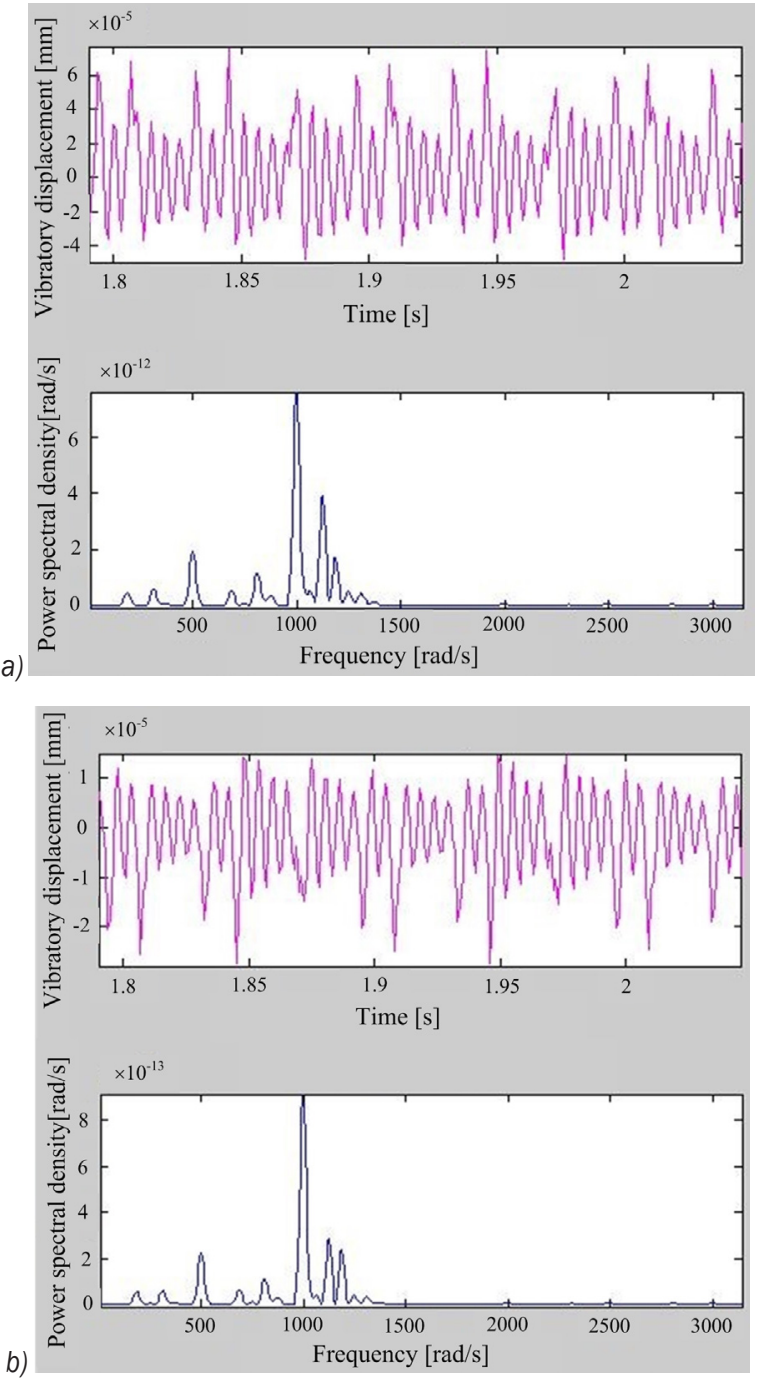

Fig. 10. Vibratory displacement of wheel-workpiece contact system with optimized numbers of grits; a) in normal direction; b) in feed direction; $\left(a_{p}=15 \mu \mathrm{m}, V_{s}=50 \mathrm{~m} / \mathrm{s}\right.$, $V_{w}=100 \mathrm{~mm} / \mathrm{s}, n=4752 \mathrm{rev} / \mathrm{min}, \mathrm{m}=6$ )

abrasive grits. It lasts approximately 20 milliseconds for grit-material interaction in the contact zone.

To evaluate the finish ground surface, surface roughness $(R a)$ is gathered by extracting the discrete values of whole surface waviness, including typical peak and bottom vertices values after each optimization strategy is implemented. According to a comparison of variable $R a$, surface with the highest quality in Fig. $11 \mathrm{~b}$ withvalue $R a$ of under $0.15 \mu \mathrm{m}$ is obtained using the best optimization strategy. Similarly, surface quality in Figs. 11c and 11a takes values $R a$ of under $0.23 \mu \mathrm{m}$ and $0.28 \mu \mathrm{m}$, respectively.

According to the analysis, the frequency and its distribution of principal and the second modes 
of machine-tool vibration varies due to the adjusted spindle speed. To achieve most stable machining process, it is necessary for the inherent dominated vibration of the machine tool to be far from the resonance frequency of material surface waviness generated by continuous adjacent active abrasive grits in terms of the regenerative principle. It is noted that an unstable machining process occurs when the micro-grinding force and vibration increase together resulting to the positive maximum of vibration energy consumption in the contact zone.

The optimization strategy with adjustment packing density or grit distribution of the abrasive wheel describes that the stable process is accomplished by increasing the grits spacing of active abrasive grits and enhancing the phase difference generated by adjacent grits. Nevertheless, the dominant frequency mode of abrasive wheel varies due to adjusted active grits in the contact zone. It means that machining stability is reconstructed under renewed modal frequency domain, which needs to take longer time intervals and more energy consumption, as well as an insignificant reduction of vibratory amplitude.

\section{CONCLUSIONS}

As the most important material removal technique, stable abrasive grinding process is necessary to achieve finish ground surface, low dimensional tolerance and further to improve the operational efficiency and lifetime of machine tool and abrasive wheel. The regenerative principle and eccentrically rotational behaviour of abrasive wheel should be taken into consideration with a systemic view, considering the interactive and excited-vibration source from internal and external conditions.

In the paper, in terms of regenerative principle and the vibratory phase characters of active abrasive grits in the contact zone, instantaneous energy consumption models are presented to demonstrate the correlation between the energy consumed to mechanical vibration and the optimal process conditions of abrasive grinding. It has be proven that at the conditions of the phase difference of continuous adjacent active abrasive grits in periodical revolution reaches to extreme values $\psi=\pi / 2$ and $\psi=3 \pi / 2$, the most stable and the most unstable machining processes would occur, respectively.

Furthermore, optimization strategies involved in spindle speed of machine tool, pack density and grit contour spacing of abrasive wheel are proposed to achieve great dynamic performance and surface finish. By comparing output results after utilizing
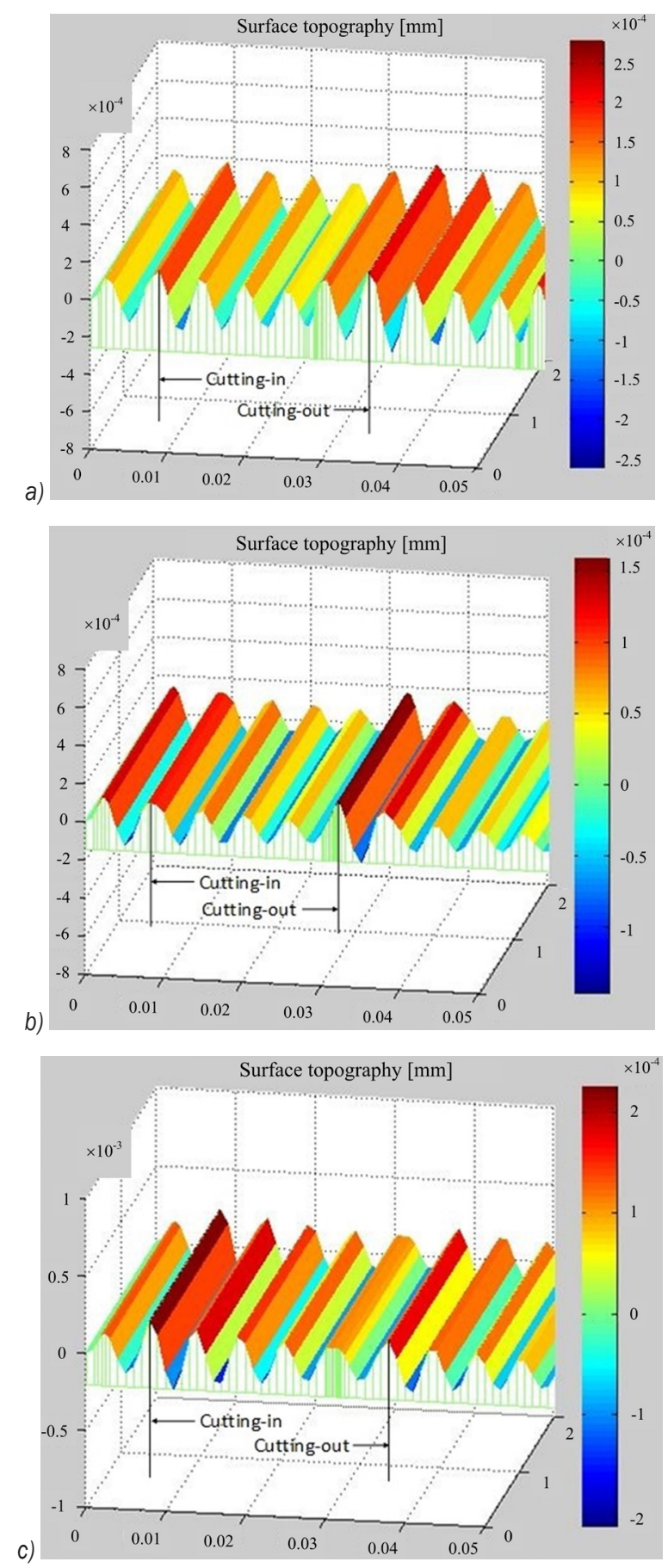

Fig. 11. 3D surface topography of material at different optimized strategies $\left(a_{p}=15 \mu \mathrm{m}, V_{\mathrm{w}}=100 \mathrm{~mm} / \mathrm{s}\right)$;

a) under original conditions $(n=4456 \mathrm{rev} / \mathrm{min}, \mathrm{m}=5)$;

b) under best conditions ( $n=4752 \mathrm{rev} / \mathrm{min}, m=5)$;

c) under optimal conditions ( $n=4752 \mathrm{rev} / \mathrm{min}, m=6$ )

the strategies, the machining stability and ground surface finish by means of adjusting spindle speed of machine tool are significantly better than those 
without optimizing pack density and contour spacing of abrasive grits. The conclusions could facilitate the optimization of principal modal distribution and the system stiffness of machine tool, abrasive wheel surface specification in consideration of the optimal machining conditions off-line.

\section{ACKNOWLEDGEMENT}

This work is supported by the State Key Program of National Natural Science of China (Grant No 51235004), the National Natural Science Foundation of China (Grant No 51575198).

\section{NOMENCLATURES}

$a_{p}$ depth of cut, [ $\left.\mu \mathrm{m}\right]$

c ratio of tangential force and radial force,

$d F_{i x}, d F_{i y}$ instantaneous forces on a single-grit in normal and feed directions, [N]

$d F_{t i}, d F_{r i}$ instantaneous forces on a single-grit in tangential and radial directions in shear plane, $[\mathrm{N}]$

$d_{s}$ grinding wheel diameter, [mm]

$f$ vibratory frequency, $[\mathrm{rad} / \mathrm{s}]$

$f_{t} \quad$ feed per revolution, $[\mu \mathrm{m}]$

$H_{i s}, H_{i s(-T)}$ dynamic displacement of current and previousgrits in radial direction, [ $\mu \mathrm{m}]$

$H_{i w}, H_{i w(-T)}$ dynamic displacement of currentand previous workpieces in radial direction, $[\mu \mathrm{m}]$

$K_{s}$ specific grinding force in per unit chip area,

$m$ pack density of abrasive wheel, [grits $/ \mathrm{mm}^{2}$ ]

$n \quad$ spindle speed of machine tool, [rev/min]

$O^{\prime} X^{\prime} Y^{\prime}$ local reference coordinate system,

$R_{i}{ }^{\prime}, R$ radius of rotating spindle of machine-tool and abrasive wheel, $[\mathrm{mm}]$

$\mathrm{t}_{0}{ }^{\prime}$ staticschip thickness, [ $\left.\mu \mathrm{m}\right]$

$t_{i}\left(\varphi_{i}\right)$ instantaneous undeformed chip thickness, $[\mu \mathrm{m}]$

$T$ discrete time interval between current and adjacent working grits, [s]

$\Delta t_{i}$ regenerative chip thickness, $[\mu \mathrm{m}]$

$V_{w}$ feed speed of workpiece, $[\mathrm{mm} / \mathrm{s}]$

$V_{s}$ peripheral speed of grinding wheel, $[\mathrm{m} / \mathrm{s}]$

$W_{i}$ mechanical energy consumed in material removal process, $[\mathrm{N} \cdot \mu \mathrm{m}]$

$X_{c}, X_{p}$ surface waviness amplitudes in radial direction, $[\mu \mathrm{m}]$

$x, y, z$ position coordinates, $[\mathrm{m}]$

$\delta_{e} \quad$ wheel eccentricity, [ $\left.\mu \mathrm{m}\right]$

$\delta t_{i}\left(\varphi_{i}\right)$ eccentric chip thickness, $[\mu \mathrm{m}]$

$\varepsilon$ comprehensive influential coefficient of grit sharpness and friction behaviour

$\varphi_{0 i}$ initial position angle of single grit, [degree]

$\varphi_{i}$ rotational position angle of single grit, [degree] $\varphi_{e i}$ relative position angle with actual wheel rotational centre, [degree]

$\omega$ angular velocity of abrasive wheel, [degree/s]

$\theta$ rotational angle of spindle of abrasive wheel, [degree]

$\lambda_{s} \quad$ grit spacing span, $[\mu \mathrm{m}]$

$\Omega$ entire included angle of grit in interaction zone, [degree]

$\psi$ phase difference between previous and current waviness trajectory. [rad]

\section{REFERENCES}

[1] Ren, J.X., Hua, D.A. (2011). Grinding Principle. Publishing House of Electronics Industry, Beijing. (in Chinese)

[2] Aurich, J.C., Kirsh, B.(2012).Kinematic simulation of highperformance grinding for analysis of chip parameters of single grains. CIRP Journal of Manufacturing Science and Technology, vol. 5, no. 3, p. 164-174, DOl:10.1016/j. cirpj.2012.07.004.

[3] Sheng, X.M., Mi, H.Q., Xie, G.Z., Shang, Z.T., Guo, L., Chen, T., Chen, G.Y., Hu, X.S., Zhang, J.M. (2010). Ultra-high SpeedGrinding Technology. China Machine Press, Beijing. (in Chinese)

[4] Chen, Y., Huang, G.Q. (2014). Development and research on the dynamics simulation system for surface grinding process with diamond wheel. Key Engineer Materials, vol. 589-590, p. 658-664, D0I:10.4028/www.scientific.net/KEM.589-590.658.

[5] Han, Z.T. (2005). Research on Grinding Chatter and Surface Topography Tolerance. China University of Mining and Technology Press, Xuzhou. (in Chinese)

[6] Zhang, D.K., Li, C.H., Zhang, Y.B., Jia, D.Z., Zhang, X.W. (2015). Experimental research on the energy ratio coefficient and specific grinding energy in nanoparticle jet MQL grinding. International Journal of Advanced Manufacturing Technology. vol. 78, no. 5-8, p. 1275-1288, DOl:10.1007/s00170-0146722-6.

[7] Jiang, J.L., Ge, P.Q., Sun, S.F., Wang, D.Y., Wang, Y.L., Yang, Y. (2016). From the microscopic interaction mechanism to the grinding temperature field: An integrated modeling on the grinding process. International Journal of Machine Tools and Manufacture, vol. 110, p. 27-42, Dol:10.1016/j. ijmachtools.2016.08.004.

[8] Zahedi, A., Tawakoli, T., Akbari, J.(2015). Energy aspects and workpiece surface characteristics in ultrasonic-assisted cylindrical grinding of alumina-zirconia ceramics. International Journal of Machine Tools and Manufacture, vol. 90, p. 16-28, D0I:10.1016/j.ijmachtools.2014.12.002.

[9] Malkin, S., Anderson, R.B. (1974). Thermal aspects of grinding: Part 1 -Energy partition. Journal of Engineering for Industry, vol. 94, no. 4, p. 1177-1183, D0l:10.1115/1.3438492.

[10] Fu, Y.C., Xu, H.J., Xu, J.H. (2002). Optimization design of grinding wheel topography for high efficiency grinding. Journal of Materials Processing Technology, vol. 129, no. 1-3, p. 118122, Dol:10.1016/s0924-0136(02)00588-5.

[11] Werner, G. (1978). Influence of work material on grinding forces. Annals of the CIRP, vol. 27, p. 243-248. 
[12] Nguyen, A.T., Butler, D.L. (2008). Correlation of grinding wheel topography and grinding performance: a study from a viewpoint of three-dimensional surface characterization. Journal of Materials Processing Technology, vol. 208, no. 1-3, p. 14-23, D0I:10.1016/j.jmatprotec.2007.12.128.

[13] Wen, X.M., Tay, A.A.O., Nee, A.Y.C.(1992). Micro-computerbased optimization of the surface grinding process. Journal of Materials Processing Technology, vol. 29, no. 1-3, p. 75-90, Dol:10.1016/0924-0136(92)90426-s.

[14] Saravanan, R., Asokan, P., Sachidanandam, M. (2002). A multiobjective genetic algorithm (GA) approach for optimization of surface grinding operations. International Journal of Machine Tools and Manufacture, vol. 42, no. 12, p. 1327-1334, DOI:10.1016/s0890-6955(02)00074-3.

[15] Darafon, A., Warkentin, A., Bauer, R. (2013). 3D metal removal simulation to determine uncut chip thickness, contact length and surface finish in grinding. International Journal of Advanced Manufacturing Technology, vol. 66, no. 9-12, p. 1715-1724, D0I:10.1007/s00170-012-4452-1.

[16] Rasim, M., Mattfeld, P., Klocke, F. (2015). Analysis of the grain shape influence on the chip formation in grinding. Journal of Materials Processing Technology, vol. 226, p. 60-68, DOI:10.1016/J.jmatprotec.2015.06.041.
[17] Denkena, B., Köhler, J., Kästner, J. (2012). Chip formation in grinding: an experimental study. Production Engineering, vol. 6, no. 2, p. 107-115, D0l:10.1007/s11740-011-0360-8.

[18] Alagumurthi, N., Palaniradja, K., Soundararajan, V. (2007). Optimization of grinding process through design of experiment (DOE) - A comparative study. Materials and Manufacturing Processes, vol. 21, no. 1, p. 19-21, D0l:10.1080/AMP200060605.

[19] Pal, D., Bangar, A., Sharma, R., Yadav, A. (2012). Optimization of grinding parameters for minimum surface roughness by Taguchi parametric optimization technique. International Journal of Mechanical and Industrial Engineering, vol. 1, p. 74-78.

[20] Tian, L., Fu, Y.C., Li, H.Y., Ding, W.F. (2015). The influence of speed on material removal mechanism in high speed grinding with single grit. International Journal of Machine Tools and Manufacture, vol. 89, p. 192-201, D0l:10.1016/j. ijmachtools.2014.11.010.

[21] Altintas, Y., Weck, M. (2004). Chatter stability of metal cutting and grinding. CIRP Annals, vol. 52, no. 2, p. 619-642, DOI:10.1016/s0007-8506(07)60032-8. 